\title{
Mycelial Biomass Production and Antioxidant Activity of Lentinus tigrinus and Lentinus sajor-caju in Indigenous Liquid Culture
}

\author{
Rich Milton R. Dulay ${ }^{1}$, Kimberly S. Flores ${ }^{2}$, Reyna C. Tiniola ${ }^{2}$, Darille Hannah \\ H. Marquez ${ }^{3}$, Aileen G. Dela Cruz ${ }^{3}$, Sofronio P. Kalaw ${ }^{1}$ and Renato G. Reyes ${ }^{1}$
}

\author{
${ }^{1}$ Center for Tropical Mushroom Research and Development, Department of Biological Sciences, College of Arts and \\ Sciences, Central Luzon State University, Science City of Munoz, Nueva Ecija, Philippines \\ ${ }^{2}$ Dr. Ramon de Santos National School, San Antonio, Cuyapo, Nueva Ecija, Philippines \\ ${ }^{3}$ Aliaga National School, Poblacion East II, Aliaga, Nueva Ecija, Philippines
}

Dulay RMR, Flores KS, Tiniola RC, Marquez DHH, Dela Cruz AG, Kalaw SP, and Reyes RG 2015 - Mycelial biomass production and antioxidant activity of Lentinus tigrinus and Lentinus sajor-caju in indigenous liquid culture. Mycosphere 6(6), 659-666, Doi 10.5943/mycosphere/6/6/2

\begin{abstract}
With the increasing demand of functional foods with antioxidant properties, it is necessary to establish new sources such as wild edible mushrooms which could provide beneficial effects to human health. Herein, we evaluated the different indigenous liquid culture media for biomass production and elucidated the free radical scavenging activity and total phenolics of Lentinus tigrinus and Lentinus sajor-caju. Results revealed that L. tigrinus efficiently grew on rice bran decoction which significantly recorded the highest yield of mycelia (11.53 g), volume loss of the medium $(24.33 \mathrm{ml})$, radical scavenging activity $(18.94 \%)$ and total phenolics $(26.59 \mathrm{mg} \mathrm{AAE} / \mathrm{g}$ sample). Similarly, rice bran decoction significantly registered the highest yield of mycelia (9.75 $\mathrm{g}$ ), volume loss of the medium $(20.95 \mathrm{ml})$, scavenging activity $(16.94 \%)$ and total phenolics $(25.60$ mg AAE/g sample) for $L$. sajor-caju. Both species also showed considerable antioxidant properties when cultured in coconut water, corn grit decoction and potato broth. Hence, it is noteworthy that both studied Lentinus species hold promising antioxidants which are influenced by different liquid media.
\end{abstract}

Key words - Mycelial biomass - Lentinus - total phenolics - liquid culture - white rot fungi.

\section{Introduction}

Mushrooms have long been considered as effective traditional medicines and now they are being recognized as functional foods because of their several bioactive potentials. Mushrooms have been shown to exhibit hypoglycaemic, hypocholesterolemic, hypotensive, antitumour, antiviral, antibiotic, and anti-inflammatory activities (Hobbs 2003, Ooio \& Liu 1999). These properties are due to the variety of potent secondary metabolites including phenolic compounds, polysaccharides, terpenes, polypeptides, steroids and others. Polysaccharide and triterpenes isolated from Ganoderma lucidum, Pleourotus sajor-caju and Lactica sativa are potent compounds against cancer (Kao et al. 2013, Moharib et al. 2014). Phenolics from mushrooms have been found to be an excellent antioxidant and synergist (Li et al. 2005) and have been associated with the inhibition of atherosclerosis and cancer (Martínez-Valverde et al. 2000). With these important attributes, mushrooms have become an attractive source for the development of nutraceuticals and drugs. 
Mushroom basidiocarp are commonly collected from the wild or cultivated on the different solid compost or lignocellulosic residues such as rice straw, sawdust, sugarcane bagasse, dried banana leaves and among others. This method of cultivation, however, is a lengthy and complex process. Thus, this present work introduces the growing of mycelia in liquid culture on the different indigenous source of nutrient medium as simple and fast alternative method of biomass production for bioactivity evaluation. Several studies have demonstrated the utilization of submerged culture of mushroom mycelia for various pharmacological properties. For instance, the antioxidant activity of submerged culture of mycelia of Paneaolus anitllarium (Dulay et al. 2015) and Agaricus brasiliensis (Carvajal et al. 2012), the antidiabetic and hypolipidemic effect of Collybia confluens mycelia produced by submerged culture in streptozotocin-diabetic rats (Yang et al. 2006), the antitumor activity of water-soluble intracellular polysaccharides extracted from cultured mycelia of Phellinus igniarius (Li et al. 2015).

Antioxidants are protective agents against oxidative damage caused by free radicals that may be related to degenerative process of aging and physiologic diseases such as diabetes, cancer, atherosclerosis, and cirrhosis (Halliwell \& Gutteridge 1999). Bioactive compounds from many natural products with antioxidant activity have been elucidated. These include tocopherol, ascorbic acid, carotenoids, and phenolics (Carvajal et al. 2012). Indeed, continues search for new bioactive natural products with antioxidant activity is of great interest by many researchers. Plants and fungi are huge group of organisms with diverse structure and chemical composition that can be tapped for this purpose.

Lentinus tigrinus and Lentinus sajor-caju are edible wood rotting basidiomycetes that have been successfully optimized on the different culture media and cultivated on the rice straw-sawdust based formulation (Dulay et al. 2012, Santos et al. 2012). Previously, our team studied the nutritional attributes and functional activities of L. tigrinus. The pileus of L. tigrinus contained higher amounts of protein $(25.9 \%)$, fat $(2.1 \%)$, ash $(7.4 \%)$ and energetic value $(142.1 \mathrm{kcal} / 100 \mathrm{~g})$ than the corresponding stipe, while its stipe contained higher amounts of total carbohydrates $(67.7 \%)$, which consists of dietary fiber $(63.0 \%)$ and reducing sugar $(4.7 \%)$, than pileus. Aside from these valuable nutrients, $100 \mathrm{mg} / \mathrm{kg}$ and $250 \mathrm{mg} / \mathrm{kg}$ dosages of lyophilized hot water extract of the fruiting body exhibited anti-diabetic activity in diabetic mice whereas the ethanolic extract of fruiting body and the immobilized secondary mycelia showed high antibacterial activities against Staphylococcus aureus (Dulay et al., 2014). In the present work, we investigated the mycelial biomass production of these two species using indigenous liquid culture broth intended for the evaluation of their radical scavenging activity and elucidation of total phenolics.

\section{Methods}

\section{Culture and inoculant}

Pure cultures of L. tigrinus and L. sajor-caju from the culture collections of the Center for Tropical Mushroom Research and Development (CTMRD), Central Luzon State University, Science City of Munoz, Nueva Ecija, Philippines were aseptically revived into sterilized potato dextrose agar (PDA) plates and incubated at $30{ }^{\circ} \mathrm{C}$ for 7 days. Mycelial discs were prepared using flame sterile cork borer (10 $\mathrm{mm}$ diameter) and served as inoculant.

\section{Mycelial production in different culture broth}

The broths of different indigenous nutrient resource were used in the evaluation of mycelial biomass production of the two Lentinus species. These include coconut water from mature coconut (Cocos nucifera), rice bran decoction (50g of Oryza sativa/L of water), local yellow corn grit decoction $(50 \mathrm{~g}$ of Zea mays/L of water) and potato sucrose broth $(250 \mathrm{~g}$ of Solanum tuberosum $/ \mathrm{L}$ of water $+10 \mathrm{~g}$ of white table sugar). Culture broth $(100 \mathrm{ml})$ were dispensed into microwavable plastic container and sterilized in an autoclave at $121 \mathrm{C}, 15 \mathrm{psi}$ for 30 minutes. There were five replicates per treatment. After cooling, each culture container was inoculated with mycelial disc and 
incubated at $32^{\circ} \mathrm{C}$ for 10 days to allow fungal growth. The mycelial mats were harvested and weighed and the volume loss of culture spent was measured.

\section{Extraction of Antioxidant Compounds}

Culture spent and mycelia were homogenized using a food processor and then ethyl acetate $(10 \mathrm{ml})$ was added into each cultured broth to extract antioxidant compounds. The ethyl acetate soluble portion was concentrated under reduced pressure and the concentrates were dissolved in ethanol for antioxidant analysis.

\section{Radical scavenging activity assay}

The free radical scavenging activity of the samples was estimated using the stable 2,2'diphenyl-1-1picrylhydrazyl (DPPH) radical following the standard method of Shimada et al. (1992) with minor modifications. A $100 \mu 1$ of test sample in ethanol was added with $5 \mu \mathrm{DPPH}$ solution (5 mg DPPH powder in $2 \mathrm{ml}$ of ethanol) in 96-well microtitter plates. The mixture was shaken vigorously and left to stand for $30 \mathrm{~min}$ in the dark, and the absorbance was then measured at $517 \mathrm{~nm}$. The inhibition of DPPH free radicals was calculated.

\section{Analysis of total phenolics}

The total phenolic content was estimated using Folin-Ciocalteu method of Slinkard \& Singleton (1977) with modifications. Sample solution $(50 \mu \mathrm{l})$ was mixed $500 \mu \mathrm{l}$ of $10 \%$ FolinCiocalteu reagent (Folin:Methanol, 1:1, v/v). After $2 \mathrm{~min}, 50 \mu \mathrm{l}$ of $7.5 \%$ saturated was added and kept in the dark for $1 \mathrm{~h}$ before absorbance was taken at $765 \mathrm{~nm}$. A calibration curve was obtained using various concentrations of ascorbic acid. The total phenolic content of the sample was expressed as mg of ascorbic acid equivalents (AAEs) per gram of sample.

\section{Statistical Analysis}

Data were analyzed using Analysis of Variance (ANOVA) in SAS Statistical Program. Means were compared using Least Significant Difference (LSD) at 5\% level of significance.

\section{Results and Discussion}

\section{Mycelial biomass production}

Evaluation of the culture conditions is an important technique in order to establish mushroom biomass production technology for pharmacological purposes. One of the most important factors in evaluating culture condition is the nutrient source or medium being used. The effect of the different culture broth on the mycelial biomass production the two Lentinus species was determined in this present work and the results are shown Figure 1. It can be seen that in both evaluated species the maximum mycelial biomass was significantly achieved in a rice bran broth having means of $9.8 \mathrm{~g}$ (for L. sajor-caju) and $11.5 \mathrm{~g}$ (for L. tigrinus). The superiority of rice bran broth could be attributed to the variety of chemical components of rice bran that support the efficient mycelial growth. Rice bran is a valuable source of carbohydrates $(49.69 \mathrm{~g})$, dietary fiber $(21 \mathrm{~g})$, sugar $(0.9 \mathrm{~g})$, sucrose $(0.5 \mathrm{~g})$, glucose $(0.2 \mathrm{~g})$, fructose $(0.2 \mathrm{~g})$, protein $(13.35 \mathrm{~g})$, and fat $(21$ g) (USDA 2012). However, in our previous works, the secondary mycelia of L. tigrinus grew best on solid medium with coconut water gulaman (local crude agar) at a $\mathrm{pH}$ range of 7.0-8.0 (Dulay et al., 2012). In some mushrooms, glucose was the best carbon source followed by molasses, starch and sucrose, while yeast extract was found to be the best nitrogen source followed by skim milk, soybean and fish powder for efficient mycelial growth of Grifola umbellata (Huang \& Liu 2008). In addition, the maximum mycelial growth of Pleurotus ostreatus was achieved in glucose as source of carbon and peptone as source of nitrogen (Nwokoye et al. 2010). However, this preference of glucose over other carbon source observed in a number of basidiomycetous fungi would exert a negative effect when the medium has higher concentrations of glucose that might be detrimental to mycelial physiology and metabolites biosynthesis (Fang \& Zhong 2002). 
Aside from the important nutritional components, minerals (calcium, iron, magnesium, phosphorous, potassium, sodium, zinc, copper, manganese and selenium), and vitamins (riboflavin, thiamin, niacin, pantothenic acid, folate, choline, alpha-tocopherol, vitamin B6 and vitamin K) are also found in rice bran (USDA 2012). Minerals at certain concentration stimulate the mycelial growth of mushroom. Iron is essential for vegetative growth of the mycelia, whereas calcium performs an important physiological role in the medium. Calcium supports maximum growth of Pleurotus that may be attributed to its role in the metabolic process such as glycolysis and respiration (Fasidi \& Olorunmaiye 1994). Moreover, good yield of $P$. florida can be obtained from medium with 5:1 carbon/nitrogen ratio, thiamine, gibberellin, calcium, and zinc. In addition, the efficiency of biomass production in rice bran broth could also be explained by the buffering capacity of this liquid medium, thus the effect of $\mathrm{pH}$ using this medium on the mycelia biomass production of these two Lentinus species must be evaluated. In contrast, low mycelial biomass production was observed when using corn grit broth as liquid medium.

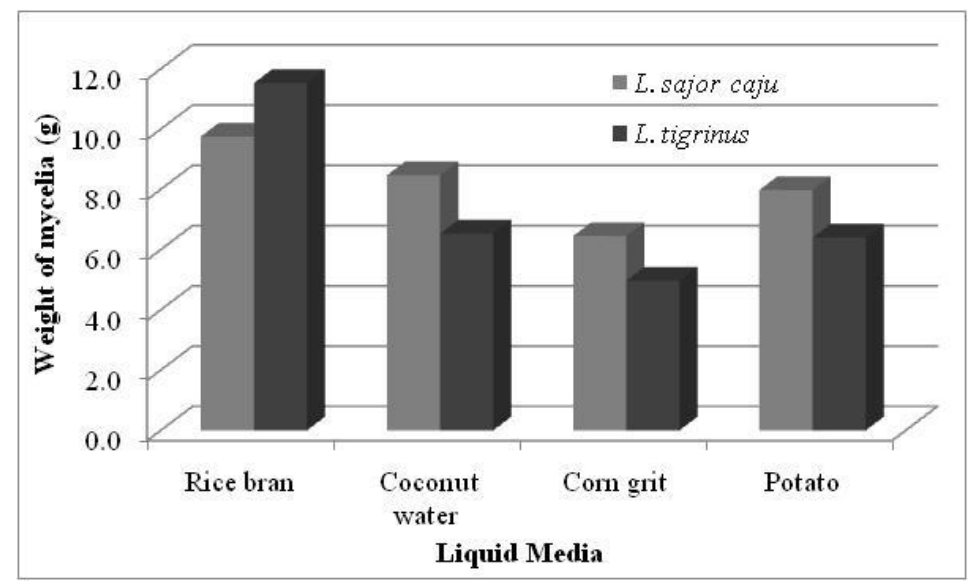

Fig. 1 - Effect of different culture broth on the mycelial biomass of the two Lentinus species after 10 days of incubation.

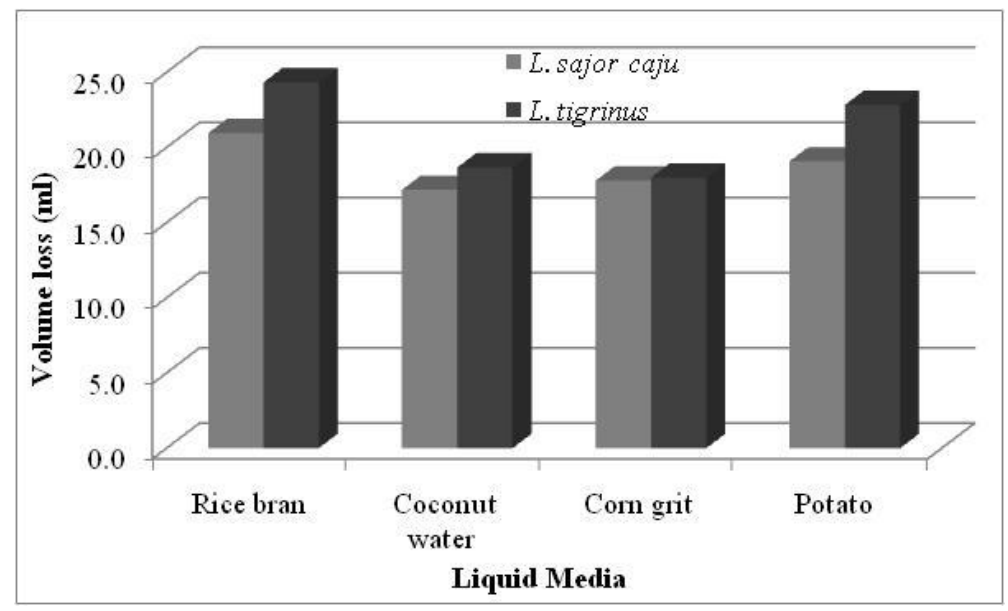

Fig. 2 - Volume loss of the culture spent of the two Lentinus species after 10 days of incubation.

Volume loss of the culture spent was also determined in this study (Figure 2). It is obvious that the medium which produced the highest mycelial biomass recorded the greatest volume loss. In both species, the maximum volume loss was observed in rice bran broth followed by potato broth. These results clearly indicate the efficient utilization of the liquid media to convert it to mycelial biomass by the two mushrooms. This finding is congruent to the observed weight loss of the lignocellulosic substrate after fruiting of cultivated mushrooms in artificial logs. 


\section{DPPH radical scavenging activity}

Antioxidant in food plays a major role in promoting healthful benefits. It reduces the risk for chronic diseases such as cancer, cardiovascular and neurodegenerative diseases (Prakash et al. 2001). In this work, the antioxidant activity using DPPH radical scavenging assay was investigated. The radical scavenging activity of the two Lentinus species grown in different indigenous liquid culture is depicted in Figure 3. Apparently, both mushrooms exhibited radical scavenging activity. However, L. tigrinus showed higher activity than L. sajor-caju in all liquid culture types. Regardless of the species, among culture types, mushroom mycelia grown in rice bran recorded the highest scavenging activity of $16.9 \%$ (for L. sajor-caju) and $18.9 \%$ (for L. tigrinus), whereas those grown in corn grit showed the lowest activity $11.3 \%$ (for L. sajor-caju) and $15.6 \%$ (for L. tigrinus). This clearly indicates that the antioxidant activity is species and culture medium dependent. Several studies have established that many mushrooms possess antioxidant property. For instance, Lentinula edodes, a relative of Lentinus species, showed antioxidant activity of $39.0 \%$ at a concentration of $1 \mathrm{mg} / \mathrm{ml}$ with an $\mathrm{EC}_{50}$ value of $4.4 \mathrm{mg} / \mathrm{mL}$. Its total phenolic content was estimated to be $70.83 \mathrm{mg}$ gallic acid equivalent (GAE) per gram of dry extract (Sasidharan et al., 2010). Moreover, Schizophyllum commune $(3.0 \mathrm{mg} / \mathrm{ml})$, Pleurotus djamour var. djamour $(5.5$ $\mathrm{mg} / \mathrm{ml})$, Pleurotus pulmonarius $(6.0 \mathrm{mg} / \mathrm{ml})$, Pleurotus djamour var. roseus $(7.5 \mathrm{mg} / \mathrm{ml})$ and Pleurotus ostreatus $(12.0 \mathrm{mg} / \mathrm{ml})$ inhibit DPPH free radicals (Gan et al. 2013). In addition, among the mushrooms evaluated by Wong et al. (2013), Auricularia polytricha showed the highest scavenging activity of $79 \%$ followed by Pleurotus eryngii had 52\%, while Flammulina velutipes and Pleurotus florida both have $23 \%$. These findings establish the great potential of mushrooms to neutralize free radicals. There are several substances responsible for antioxidant potentials of many mushrooms. These include $\beta$-glucan, tocopherols, niacin, flavin, pyridoxine, ascorbate, shikimate, malate, fumarate, monoterpenoid, diterpenoid, lipids, hydrophobins and trace elements such as selenium (Yim et al. 2010, Aggarwal et al. 2012).

\section{Total phenolic content}

Phenolics are one of the groups of nonessential dietary components present in plants and mushrooms as secondary metabolites. Figure 4 presents the total phenolic content of the two Lentinus species as influenced by the different liquid culture media. L. tigrinus mycelia had higher phenolic content than L. sajor-caju mycelia. Regardless of the species, rice bran broth supports the efficient production of not only mycelial biomass but most importantly its phenolic content (25.6 mg AAE/g sample for L. sajor-caju and $26.6 \mathrm{mg}$ AAE/g sample for L. tigrinus). In contrast, corn grit broth had the lowest phenolic content (19.6 mg AAE/g sample for $L$. sajor-caju and $22.1 \mathrm{mg}$ AAE/g sample for L. tigrinus). These result gathered strongly dictates that the phenolic content of mushroom is species and culture media dependent. Phenolics exhibited antioxidant activities and may interfere physiological processes of cancers, leading to cancer risk reduction (Hollman 2001). The bioactivity of phenolics may be related to their ability to chelate metals, inhibit lipoxygenase, and scavenge free radicals (Mallavadhani et al. 2006).

In conclusion, we established the mycelial biomass production of the two Lentinus species in indigenous liquid culture. The mycelial biomass production and antioxidant activity of both mushrooms showed species and culture media dependent. Rice bran broth produced the maximum mycelial biomass and recorded the highest antioxidant properties by DPPH radical scavenging activity and total phenolic content. Thus, this medium could be used in efficient production of mushroom biomass and valuable bioactive metabolites. With the significant attributes of these two mushrooms when grown on rice bran broth in liquid culture, several potential biological activities is highly expected. In the future, it is recommended the elucidation, characterization and identification of novel compounds responsible for these bioactivities must be investigated. 


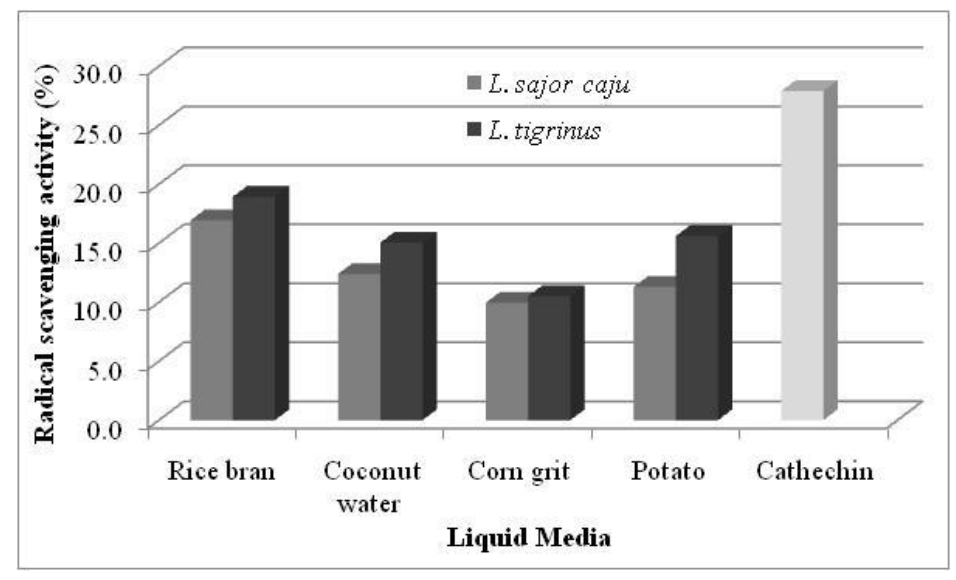

Fig. 3 - Radical scavenging activity of the two Lentinus species in different indigenous liquid culture.

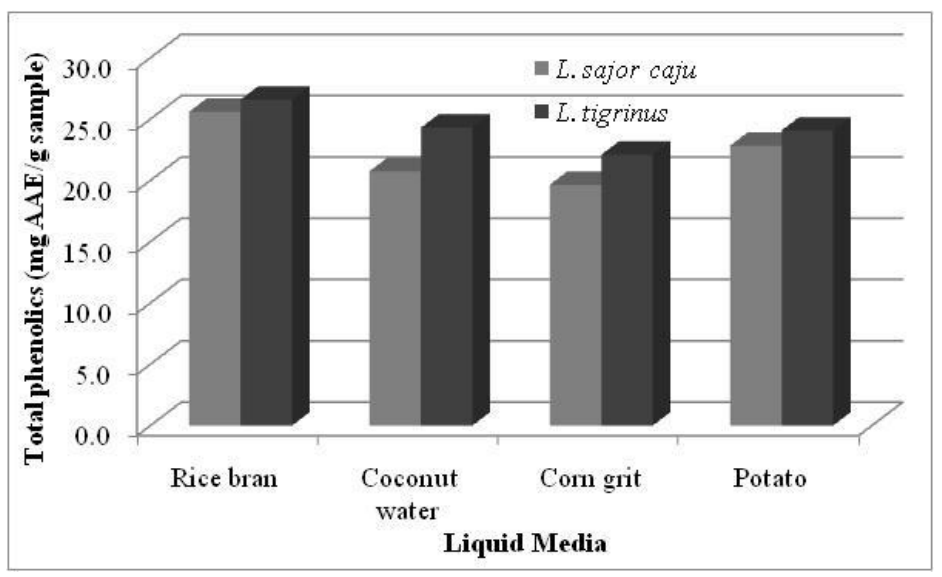

Fig. 4 - Phenolic contents of the two Lentinus species in different indigenous liquid culture.

\section{Acknowledgement}

The remarkable assistance of the Center for Tropical Mushroom Research and Development staffs during the conduct of this study is gratefully acknowledged.

\section{References}

Aggarwal P, Sharma P, Sharma S, Aggarwal J. 2012 - Antioxidant mushroom: a review. International Research Journal of Pharmacy 3(6), 65-70.

Carvajal AESS, Koehnlein EA, Soares AA, Eler GJ, Nahshima ATA, Bracht A, Peralta RM. 2012 - Bioactives of fruiting bodies and submerged culture mycelia of Agaricus brasiliensis (A. blazei) and their antioxidant properties. LWT- Food Science and Technology 46, 493-499.

Dulay RMR, Arenas MC, Kalaw SP, Reyes RG, Cabrera EC. 2014 - Proximate composition and functionality of the culinary-medicinal tiger sawgill mushroom, Lentinus tigrinus (Higher basidiomycetes), from the Philippines. International Journal of Medicinal Mushrooms 16(1), 85-94.

Dulay RMR, Cabalar AC, De Roxas MJB, Concepcion JMP, Cruz NE, Esmeralda M, Jimenez N, Aguilar JC, De Guzman EJ, Santiago JQ, Samoy JR, Bustillos RG, Kalaw SP, Reyes RG. 2015 - Proximate composition and antioxidant activity of Panaeolus antillarium, a wild coprophilous mushroom. Current Research in Environmental \& Applied Mycology 5(1), 5259. 
Dulay RMR, Kalaw SP, Reyes RG, Cabrera EC, Alfonso N. 2012 - Optimization of culture conditions for mycelial growth and basidiocarp production of Lentinus tigrinus (Bull.) Fr., a new record of domesticated wild edible mushroom in the Philippines. Philippine Agricultural Scientist 95(3), 278-285.

Fang QH, Zhong JJ. 2002 - Submerged fermentation of higher fungus Ganoderma lucidum for production of valuable bioactive metabolites-ganoderic acid and polysaccharide. Biochemical Engineering Journal 10, 61-65.

Fasidi I, Olorunmaiye K. 1994 - Studies on the requirements for vegetative growth of Pleurotus tuber-regium (fr.) Singer, a Nigerian mushroom. Food Chemistry 50, 397-401.

Gan CH, Nurul AB, Asmah R. 2013 - Antioxidant analysis of different types of edible mushrooms (Agaricus bisporus and Agaricus brasiliensis). International Food Research Journal 20(3), 1095-1102.

Halliwell B, Gutteridge JMC. 1999 - The definition and measurement of antioxidant in biological systems. Free Radical Biology and Medicine 18(1), 125-126.

Hobbs CH. 2003 - An Exploration of Tradition, Healing and Culture. In Medicinal Mushrooms; Michael, M., Ed.; Botanica Press: Redondo Beach, California, USA.

Hollman PCH. 2001 - Evidence for health benefits of plant phenols: local or systematic effects? Journal of the Science and Food Agriculture 81, 842-852.

Huang HC, Liu YC. 2008 - Enhancement of polysaccharide production by optimization of culture conditions in shake flask submerged cultivation of Grifola umbellata. Journal of Chinese Institute of Chemical Engineers 39, 307-311.

Kao CHJ, Jesuthasan AC, Bishop KS, Glucina MP, Ferguson LR. 2013 - Anti-cancer activities of Ganoderma lucidum: active ingredients and pathways. Functional Foods in Health and Disease 3(2), 48-65.

Li SC, Yang XM, Ma HL, Yan JK, Guo DZ. 2015 - Purification, characterization and antitumor activity of polysaccharides extracted from Phellinus igniarius mycelia. Carbohydrate Polymers 133, 24-30.

Li L, Ng TB, Zhao L. 2005 - Antioxidant activity with content of phenolics in extracts from the culinary-medicinal abalone mushroom Pleurotus abalones (Agaricomycetideae). International Journal of Medicinal Mushrooms 2005, 237-242.

Mallavadhani U, Sudhakar A, Sathyanarayana KVS, Mahapatra A, Li W, Richard B. 2006 Chemical and analytical screening of some edible mushrooms. Food Chemistry 95, 58-64.

Martínez-Valverde I, Periago MJ, Ros G. 2000 - Nutritional importance of phenolic compounds in the diet. Arch Latinoam Nutrition 50(1), 5-18.

Moharib SA, Maksoud N, Ragab HM, Shehata MM. 2014 - Anticancer activities of mushroom polysaccharides on chemically-induced colorectal cancer in rats. Journal of Applied Pharmaceutical Science 4(07), 054-063.

Nwokoye AI, Kuforiji OO, Oni PI. 2010 - Studies on mycelial growth requirements of Pleurotus ostreatus (Fr.) Singer. International Journal of Basic \& Applied Sciences 10(2), 47-53.

Ooio VE, Liu F. 1999 - A review of pharmacology activities of mushroom polysaccharides. International Journal of Medicinal Mushrooms 1, 195-206.

Prakash A, Rigelhof F, Miller E. 2001 - Antioxidant activity. Medical Laboratories Analytical Progress. http://www.medlabs.com/Downloads/Antiox_acti_pdf.

Santos KK, Dulay RMR, Kalaw SP, Reyes RG. 2012 - Morphogenesis of Lentinus sajor-caju Fr. In Transactions of the National Academy of Science and Technology (Philippines) 34(1), 79.

Sasidharan S, Aravindran S, Latha LY, Vijenthi R, Saravanan D, Amutha S. 2010 - In vitro antioxidant activity and hepatoprotective effects of Lentinula edodes against paracetamolinduced hepatotoxicity. Molecules 15, 4478-4489.

Shimada K, Fujikawa K, Yahara K, Nakamura T. 1992 - Antioxidative properties of xanthan on the autoxidation of soybean oil in cyclodextrin emulsion. Journal of Agricultural and Food Chemistry 40, 945-948. 
Slinkard K, Singleton VL. 1977 - Total phenol analyses: automation and comparison with manual methods. American Journal of Enology and Viticulture 28, 49-55.

USDA. 2012 - Nutritional info of rice bran, crude vs. oat bran, raw. SkipThePie.org. Available at http://skipthepie.org/cereal-grains-and-pasta/rice-bran-crude/compared-to/oat-bran-raw/

Wong FC, Chai TT, Tan SL, Yong AL. 2013 - Evaluation of bioactivities and phenolic content of selected edible mushrooms in Malaysia. Tropical Journal of Pharmaceutical Research 12(6), 1011-1016.

Yang K, Jeong SC, Lee HJ, Sohn DH, Song CH. 2006 - Antidiabetic and hypolipidemic effects of Collybia confluens mycelia produced by submerged culture in streptozotocin-diabetic rats. Archives of Pharmacalogy Research 29(1), 73-79.

Yim HS, Chye FY, Tan CT, Ng YC, Ho CW. 2010 - Antioxidant activities and total phenolic content of aqueous extract of Pleurotus ostreatus (cultivated oyster mushroom). Malaysian Journal of Nutrition 16(2), 281-291. 